\title{
NILAI KARAKTER RAJA SUMEDANG DALAM SASAKALA DARMARAJA
}

\author{
Windu Mandela \\ STKIP Sebelas April Sumedang, Jl Angkrek Situ No 19 Sumedang \\ Email: windusaja667@gmail.com
}

\begin{abstract}
Individuals who have the character will bring a good impact for himself, religion, even for the nation and country. The abundance of folklore should be an alternative teaching material at school. The reason, in folklore is characterized the value of characters that can be used as an alternative learning. There are 18 character values issued by Kementrian Pendidikan Nasional (Kemendiknas). In abundant folklore is characterized the value of characters that can be applied in teaching and learning activities. Sasakala Darmaraja, is one of the folklore that developed in Sumedang Regency. In this folklore found some character values that have been formulated Kemendiknas. The type of study conducted is qualitativedescriptive. Researchers review by describing the parts of the story so that obtained three character values. The value of the character is, the spirit of nationality, hard work, and responsibility. Strike of foreign culture through the development of technology and information will be a problem if we do not have a strong character.
\end{abstract}

Keywords:

Character; folklore; qualitative

\begin{abstract}
Abstrak
Individu yang memiliki karakter akan membawa dampak yang baik bagi dirinya, agama, bahkan bagi bangsa dan negaranya. Melimpahnya cerita rakyat hendaknya menjadi sebuah alternative bahan ajar di sekolah. Pasalnya, dalam cerita rakyat tertuang nilai karakter yang dapat dimanfaatkan sebagai alternative pembelajaran. Ada 18 nilai karakter yang dikeluarkan oleh Kementerian Pendidikan Nasional (Kemendiknas). Dalam cerita rakyat yang melimpah tersebut tertuang nilai karakter yang dapat diaplikasikan dalam kegiatan belajar mengajar. Sasakala Darmaraja, adalah salahsatu cerita rakyat yang berkembang di Kabupaten Sumedang. Dalam cerita rakyat ini ditemukan beberapa nilai karakter yang telah dirumuskan Kemendiknas. Jenis kajian yang dilakukan adalah kualitatif-deskriptif. Peneliti menelaah dengan mendeskripsikan bagian-bagian cerita sehingga didapat tiga buah nilai karakter. Nilai karakter tersebut adalah, semangat kebangsaan, kerja keras, dan tanggung-jawab. Gempuran budaya asing melalui perkembangan teknologi dan informasi akan menjadi suatu permasalahan apabila kita tidak memiliki karakter yang kuat.
\end{abstract}

\section{Kata kunci:}

Karakter; folklore; kualitatif

\section{A. PENDAHULUAN}

Perkembangan teknologi dan informasi tidak dapat dibendung. Dalam perjalanannya, tidak semua yang berasal dari asing memiliki manfaat. Sebagian budaya asing yang disebarkan melalui teknologi tentu tidak cocok untuk diserap oleh masyarakat Indonesia. Indonesia yang memiliki adat ketimuran tentu memiliki banyak pertentangan dengan dunia barat dari berbagai sisi.

Film, adalah sebuah hasil karya manusia yang di dalamnya terdapat pesan. Pesan ini tentu beragam tergantung maksud dan tujuan yang ingin disampaikan. Ada banyak sekali film yang diperuntukan bagi anak-anak. Meskipun terdapat pesan moral yang diberikan masih ada beberapa adegan yang sebenarnya bertolak belakang dengan kebiasaan adat ketimuran kita.

Kita dapat ambil contoh film yang diadaptasi dari cerita rakyat. Putri Salju, salahsatu cerita dari luar negeri dan telah difilmkan ini sebenarnya memiliki pesan moral didalamnya. Hanya saja, ada beberapa adegan yang tidak cocok dengan karakter budaya tanah air. Diceritakan bahwa putri salju tengah 
pingsan kemudian ada pangeran yang datang dan mencium Putri Salju.

Peristiwa tersebut tentu sangat bertolak belakang dnegan budaya kita dan malah akan memberi contoh yang tidak baik. Masih ada lagi cerita yang diperuntukan bagi anak dari luar negeri akan tetapi tidak sesuai dengan budaya kita. Maka dari itu, kita perlu menggali lebih jauh lagi kearifan lokal yang melimpah di sekitar kita.

Beberapa penelitian mengatakan, dalam kearifan lokal terdapat nilai karakter. Seperti yang dilakukan Fitra Youpika dan Darmiyati Zuchdi Program Pascasarjana Universitas Negeri Yogyakarta, mereka meneliti tentang Cerita Rakyat Suku Pasemah Bengkulu. Hasilnya, Nilai pendidikan karakter yang ditemukan dalam legenda, yaitu pemberani, tanggung jawab, peduli sosial, disiplin, rendah hati, dan religius.

Begitupun dengan Muh. Jaelani Al-Pansori dan Herman Wijaya, mereka meneliti NILAI PENDIDIKAN KARAKTER DALAM CERITA RAKYAT SASAK. Hasilnya, pendidikan karakter yang ditemukan pada cerita sasak dianataranya adalah nilai pendidikan kepercayaan, rasa hormat, peduli, adil, tanggungjawab, kewarganegaraan, belajar sepanjang hayat dan berpikir kritis, rajin dan cakap.

Hornby dan Pornwell, 1972: 49, menyatakan karakter adalah kualitas mental atau moral, kekuatan moral, nama atau reputasi. Dalam psikologi karakter adalah kepribadian ditinjau dari titik tolak etis atau moral, misal kejujuran seseorang yang biasanya mempunyai kaitan dengan sifat-sifat yang relative tetap (Dari, 1982: 29). Sejalan dengan yang diungkapkan oleh Syaodih \& Agustin (2013) karakter adalah kualitas moral seseorang dalam bertindak dan berprilaku sehingga menjadi ciri khas individu dan dapat membedakan dirinya dengan individu-individu lainnya.

Sementara itu, Goleman

menyatakan bahwa karakter merupakan kecerdasan emosional. Berdasar beberapa pendapat di atas dapat disimpulkan bahwa karakter adalah nilai tingkahlaku manusia yang bersinggungan dengan diri sendiri, antar manusia, Tuhan, lingkungan dan kebangsaan yang diwujudkan dalam pikiran, sikap, perasaan, perkataan, dan perbuatan berdasarkan norma-norma agama, hukum, tata krama, budaya, dan adat istiadat.

\section{B. HASIL DAN PEMBAHASAN}

Tembong Agung, adalah sebuah kerajaan cikal bakal lahirnya Sumedang Larang. Secara geografis, wilayah kerajaan Tembong Agung berada di Kecamatan Darmaraja, Kab. Sumedang. Darmaraja memiliki ceritanya tersendiri. Hal tersebut tidak dapat dipisahkan dari kerajaan Tembong Agung itu sendiri. Nama Tembong Agung pun diganti menjadi Sumedang Larang oleh Prabu Tadjimalela. Tatkala Prabu Tadimalela akan menurunkan tahta kerajaannya. Kedua anaknya tidak berkenan untuk menjadi raja dan saling mempersilahkan untuk menjadi raja.

Cerita tersebut pun dilestarikan secara turun temurun dan menjadi sebuah cerita rakyat. Ada tiga tokoh dalam cerita ini, yang pertama adalah Prabu Tadjimalela selaku ayah yang akan menurunkan tahta kerajaan. Prabu Lembu Agung, anak pertama dari Prabu Tadjimalela, dan Prabu Gajah Agung.

\section{Ringkasan Cerita}

Prabu Tadjimalela, merupakan raja pertama di kerajaan Sumedang Larang, yang diwariskan dari ayahnya Prabu Guru Aji putih. Sebelumnya, Sumedang Larang bernama Tembong Agung, akan tetapi oleh Tadjimalela diubah menjadi Sumedang Larang. Begitupun 
selanjutnya, Tadjimalela akan menurunkan tahta kerajaan kepada anaknya.

Tadjimalela memiliki dua anak yang bernama Lembu Agung dan Gajah Agung, menurut tradisi leluhur seharusnya Lembu Agung yang menjadi raja. Akan tetapi, Lembu Agung menolak untuk menjadi raja dan mengisyaratkan adiknya Gajah Agung menjadi raja. Kedua anak Tadjimalela memiliki banyak kesamaan terutama dari segi fisik, sebab keduanya hanya berbeda dua tahun saja.

Melihat kedua anak tersebut tidak ada yang menerima menjadi raja, akhirnya Tadjimalela memberi tes untuk bertapa selama empat puluh hari di Gunung Nurmala (Sangkanjaya). Setelah empat puluh hari lamanya, mereka diperintahkan untuk membelah kelapa. Kelapa siapa yang memiliki air maka tidak berhak menjadi raja.

Setelah dibelah, kelapa milik Gajah Agung ada airnya, dan dia merasa adiknya yang berhak menjadi raja. Akan tetapi, Gajah Agung tidak menerima begitu saja dan tetap bersikukuh Lembu Agung harus menjadi raja karena harus mengikuti aturan leluhur dan tidak ingin terjadi perpecahan di kemudian hari.

Melihat alotnya penunjukan siapa yang jadi raja akhirnya Tadjimalela menengahinya. Akhirnya dengan segala pertimbangan Lembu Agung menerima untuk menjadi raja. Akan tetapi dia hanya darma ngarajaan, cuma berbakti sebagai raja.

\section{Analisis tokoh}

\section{a. Prabu Tadjimalela}

Prabu Tadjimalela ialah raja pertama Sumedang Larang, yang sebelumnya mendapat tahta dari ayahnya yang bernama Prabu Guru Aji Putih. Sebelumnya Sumedang Larang bernama Tembong Agung, akan tetapi diubah oleh Tadjimalela menjadi Sumedang Larang. Prabu Tadjimalela dalam cerita ini memiliki nilai karakter tanggung-jawab, hal ini dapat dilihat dalam kutipan berikut:

"Jadi, Eyang Gajah Agung walaupun berhak teguh terhadap pendiriannya tidak ingin mengubah tatanan tradisi penyerahan tahta kekuasaan. Pada akhirnya, serah menyerahkan, yang ini kakak saja yang jadi raha, yang ini adik saja yang jadi raja, akhirnya saling menuduh sampai berkelahi, mungkin dari nafsunya, dari hak. Pada akhirnya tidak ada yang kala, lalu dipisah oleh ayahnya, akhirnya dipanggil ke kraton."

Sebagai seorang Ayah dari Lembu Agung dan Gajah Agung, Tadjimalela memiliki tanggung jawab untuk menengahi perkelahian kedua anaknya. Tadjimalela mencoba mencari jalan keluar siapa yang seharusnya menjadi raja. Apabila tidak demikian mungkin saja akan terjadi hal yang tidak diinginkan terlebih permasalahan yang ingin diselesaikan, yakni mencari pengganti dirinya tidak akan terwujud.

Semangat kebangsaan terdapat juga dalam sikap Tadjimalela. Hal ini dapat dilihat dari kutipan berikut:

"Sangat dimengerti oleh Ayahanda, akhirnya tetap patuh kepada pendapat-pendapat Gajah Agung. Lalu diserahkan kembali kepada Lembu Agung. "demikian jawaban adik engkau, bagaimana?".

\begin{tabular}{|c|}
\hline $\begin{array}{l}\text { Sebelumnya, Gajah } \\
\text { mengisyaratkan agar kerajaan } \\
\text { diturunkan kepada anak pertama, } \\
\text { Agung. Gajah Agung tidak mengir } \\
\text { pada suatu hari terjadi perpecahan } \\
\text { perebutan tahta kekuasaan. Hal de } \\
\text { pun dapat dipahami oleh Tadjimalel }\end{array}$ \\
\hline
\end{tabular}

\section{b. Prabu Lembu Agung}


Prabu Lembu Agung ialah anak pertama dari Tadjimalela, dalam pribadi Lembu Agung dalam cerita ini ialah memiliki nilai karakter tanggung jawab. Hal tersebut dapat dilihat dari kutipan berikut:

"Ketika dibelah yang Lembu Agung ada airnya, yang Gajah Agung tidak ada airnya. Akhirnya sadar Lembu Agung, yang harus jadi raja ialah adiknya, tapi Gajah Agung menolak, walapun itu kias untuk menentukan yang jadi raja tidak bisa begitu."

Kutipan di atas mengisyaratkan nilai tanggung jawab yang terdapat dalam diri Lembu Agung. Pepatah yang diberikan Tadjimalela ialah kelapa siapa yang ada airnya maka tidak berhak menjadi raja. Pepatah ini dipegang oleh Lembu Agung meskipun pada akhirnya Gajah Agung menolaknya.

Selain nilai karakter tanggung jawab, dalam cerita ini Lembu Agung memiliki karakter Kerja Keras. Hal ini dapat dilihat dari kutipan berikut:

"Tafakur selama empat puluh malam di Gunung Nurmala, menahan lapar dan haus. Lulus dari tes spiritual, kemudian dibelah, dibelahnya oleh pedang Kamkam peninggalan Eyang Prabu Guru Aji Putih."

Kutipan di atas memberi keterangan bahwa selama empat puluh hari Lembu Agung dan Gajah Agung berpuasa menahan lapar dan haus. Hal tersebut merupakan nilai karakter dari kerja keras untuk menuntaskan sebuah tugas.

\section{c. Prabu Gajah Agung}

Prabu Gajah Agung merupakan adik dari Lembu Agung, hanya saja kecakapan yang hampir sama dengan kakaknya, dan usia yang terpaut hanya dua tahun membuat Tadjimalela bingung untuk memilih siapa yang pantas menjadi raja. Ada beberapa nilai karakter dalam cerita ini yang terdapat dalam diri Gajah
Agung, di antaranyan ialah tanggung jawab. Hal ini dapat dilihat dari kutipan berikut:

"Ketika dibelah yang Lembu Agung ada airnya, yang Gajah Agung tidak ada airnya. Akhirnya sadar Lembu Agung, yang harus jadi raja ialah adiknya, tapi Gajah Agung menolak, walapun itu kias untuk menentukan yang jadi raja tidak bisa begitu. Sebab Gajah Agung tidak mau mengubah tradisi penyerahan tahta kerajaan."

Kutipan di atas menggambarkan tanggung jawab Gajah Agung terhadap tradisi yang telah berlangsung secara turun temurun. Hal tersebut merupakan tanggung jawab yang harus diembannya sebagai keluarga kerajaan. Hal serupa dapat juga dilihat dari kutipan berikut:

"mohon maaf ayahanda, bukannya menolah tanda kasih dari gaib dan kepercayaan ayahanda, hanya diri saya taat kepada tali leluhur utamanya kepada tradisi penyerahan tahta kekuasaan agar tidak menimbulkan perebutan kekuasaan seperti di kerajaan lain. Jadi untuk Sumedang Larang jangan sampai seperti itu,’.

Selain nilai karakter tanggung jawab, kerja keras pun terdapat dalam diri Gajah Agung. Hal tersebut dapat dilihat dari kutipan berikut:

"Tafakur selama empat puluh malam di Gunung Nurmala, menahan lapar dan haus. Lulus dari tes spiritual, kemudian dibelah, dibelahnya oleh pedang Kamkam peninggalan Eyang Prabu Guru Aji Putih."

Nilai karakter semangat kebangsaan pun ada dalam diri Gajah Agung, ketika diberikan tahta menjadi raja, Gajah Agung berdalih tidak ingin terjadi kekacauan pada suatu ketika, seperti halnya perebutan 
kekuasaan. Hal ini dapat dilihat dari kutipan berikut:

"Ketika dibelah yang Lembu Agung ada airnya, yang Gajah Agung tidak ada airnya. Akhirnya sadar Lembu Agung, yang harus jadi raja ialah adiknya, tapi Gajah Agung menolak, walapun itu kias untuk menentukan yang jadi raja tidak bisa begitu. Sebab Gajah Agung tidak mau mengubah tradisi penyerahan tahta kerajaan, dikhawatirkan akan menimbulkan konflik perebutan tahta kekuasaan.“

Setelah dilakukan kajian, Sasakala Darmaraja memiliki tiga nilai karakter yang terdapat dalam tokohnya. Ketiga nilai karakter tersebut adalah kerja keras, semangat kebangsaan, dan tanggung jawab.

\section{SIMPULAN}

Berdasarkan kajian nilai karakter Raja Sumedang pada Sasakala Darmaraja peneliti dapat menjumpai nilai karakter Tanggungjawab, Semangat Kebangsaan dan Kerja Keras. Folklore ini diharapkan dapat dijadikan sebuah alternative bahan ajar. Folklore yang melimpah adalah kekayaan yang luar biasa dan harus dimanfaatkan sebagai filter budaya asing yang sebagian kurang berfaedah.

Mengingat banyaknya folklore di tanah air, peneliti harapkan agar peneliti lain mengkaji folklore yang lain. Setiap folklore memiliki karakteristiknya dan system kearifan lokalnya masing-masing. Maka akan sangat relevan apabila sebuah folklore asal siswa diajarkan pada siswa tersebut. Pasalnya akan sangat berguna dalam kehidupannya sehari-hari karena memiliki karakteristiknya tersendiri.

\section{DAFTAR PUSTAKA}

Al-Pansori, Muh. Jaelani: dan Herman Wijaya. NILAI-NILAI PENDIDIKAN KARAKTER DALAM CERITA RAKYAT SASAK (PENDEKATAN PRAGMATIK). Jurnal Educati Vol. 9 No. 2, hal. 307-325. 2014.

Goleman, D. Emotional Intelligence. Bentam Book, New York. Jeferson City. 1995.

Hornby \& Parnwell. Learner's Dictionary. Kuala Lumpur : Oxford University Press. 1972.

Kementerian Pendidikan Nasional. Pengembangan Pendidikan Budaya dan Karakter Bangsa - Pedoman Sekolah, Jakarta: Badan Penelitian dan Pengembangan. 2010.

Syaodih, E. dan Agustin, M. Penelitian Bidang Keilmuan: Penerapan Permainan Tradisional "Kaulinan Barudak" untuk mengembangkan Nilai Karakter Anak. Bandung: UPI. 2013.

Youpika, Fitra; dan Darmiyati. 2016. NILAI PENDIDIKAN KARAKTER CERITA RAKYAT SUKU PASEMAH BENGKULU DAN RELEVANSINYA SEBAGAI MATERI PEMBELAJARAN SASTRA. Jurnal Pendidikan Karakter, Tahun VI, Nomor 1. April.

\section{Wawancara}

Wangsa, Aki (Budayawan), wawancara oleh Windu Mandela dosen STKIP Sebelas April Sumedang. Tanggal 21 Juni 2017. 